\title{
PERSPECTIVAS DE ESTUDANTES EM SITUAÇÃO DE VESTIBULAR SOBRE AS COTAS UNIVERSITÁRIAS ${ }^{1}$ PERSPECTIVES OF STUDENTS PREPARING FOR UNIVERSITY ENTRANCE EXAMINATION ABOUT UNIVERSITY QUOTAS
}

\author{
Fernanda Vieira Guarnieri e Lucy Leal Melo-Silva \\ Universidade de São Paulo, Ribeirão Preto, Brasil
}

\section{RESUMO}

As Cotas Universitárias são medidas que visam a ampliar possibilidades de ingresso no ensino superior para grupos sociais específicos. É um tema abrangente que aborda desde a falta de vagas para o ensino superior, até aspectos que relacionam subjetividade e pertença étnico-racial. O objetivo do presente estudo consiste em investigar as opiniões de vestibulandos sobre as Cotas. Participaram do estudo 107 estudantes de cursos pré-vestibulares, distribuídos em Grupo A (cursinhos alternativos; n=53) e Grupo B (cursinhos particulares; $n=54$ ). O estudo foi realizado em duas etapas: (1) aplicação do Questionário COTAS e (2) realização de entrevista individual. Os resultados indicam que a temática Cotas Universitárias é explorada superficialmente e de modo estereotipado pelos estudantes. O critério social foi mais aceito pelos participantes do que o critério étnico-racial na definição de Cotas. Por fim, ressalta-se a necessidade de promover debates sobre Cotas universitárias, no intuito de regulamentar, fiscalizar e avaliar as medidas.

Palavras-chave: cotas universitárias; ensino superior; curso pré-vestibular, acesso à universidade.

\begin{abstract}
University Quotas are measures that aim to increase the possibilities of entrance into Higher Education by specific social groups. That is an embracing issue that addresses not only the scarceness of vacancies in Higher Education, but also aspects about subjectivity and ethnic-racial issues. This study aims to analyze the opinion about University Quotas by a group of students attending preparatory courses. In this study, 107 students have participated and were distributed into two groups: Group A (communitarian courses, $n=53$ ) and Group B (private courses, $n=54$ ). The study was conducted in two stages: (1) application of QUOTAS' Questionnaire, and (2) individual interviews. Results point out that the University Quotas issue is superficially explored and stereotyped by students. The social criteria to define Quotas was more accepted by them than the ethnic-racial one. Finally, the paper proposes that debates about University Quotas should be furthered targeting to supervise practices.
\end{abstract}

Keywords: university quotas; higher education; preparatory courses, university entrance.

\section{Introdução}

As Cotas Universitárias são medidas voltadas para grupos sociais específicos e visam a ampliar as possibilidades de ingresso no Ensino Superior. Os conteúdos históricos e étnico-raciais são marcas que diferenciam essas de outras medidas que também se definem como ações afirmativas. Tais conteúdos, na medida em que evidenciam as relações de poder construídas historicamente entre brancos e negros, trazem também a necessidade de se reavaliar a harmonia mestiça ou o mito de democracia racial no contexto brasileiro.
Entende-se por ações afirmativas medidas de caráter público ou privado que objetivam corrigir mecanismos de exclusão associados a minorias étnicas, raciais ou sexuais (Guimarães, 1997). Funcionam da seguinte forma: por um tempo determinado, privilegiam-se os que estão em situação de desvantagem, buscando-se, por fim, o equilíbrio. Dessa forma, os Direitos Universais passam a ser usufruídos de fato pela totalidade dos indivíduos de uma sociedade. O tempo de duração dessas medidas varia de acordo com seus propósitos ou da situação em que se pretende intervir. Trata-se, basicamente, de medidas de caráter social para favorecer, a 
partir de posições iguais, a concorrência por oportunidades. Portanto, o seu objetivo final é colocar todos os membros de uma determinada sociedade em condições de participarem da conquista do que é vitalmente mais significativo (Moehlecke, 2004).

Um estudo sobre as ações afirmativas no Ensino Superior foi realizado por Guarnieri e Melo-Silva (2007), identificando três linhas de pensamento que permearam a dinâmica da discussão sobre ações afirmativas no Ensino Superior, a partir da revisão na literatura no período de 2000 a 2005, em duas bases de dados, Scopus e Jstor. O referido estudo de revisão da literatura, do tipo estado da arte, analisa o corpo de conhecimento já construído a respeito da temática: ações afirmativas no Ensino Superior. Os dados foram organizados em três unidades de análise (Bardin, 1977): (1) pensamento dicotômico contra ou a favor, (2) exploração de conceitos de diversidade e (3) reflexões dialéticas. A primeira é marcada pela exposição de teorias e hipóteses direcionadas unilateralmente, ora por oposição, ora por defesa das ações afirmativas nas universidades; na segunda, há exploração de conceitos positivos sobre diversidade, caracterizada pela valorização dos efeitos positivos atribuídos ao cultivo e valorização da diferença; e os estudos organizados na terceira categoria focalizam reflexões dialéticas, definidas como produções reflexivas e críticas sobre as ações afirmativas, sendo abordadas em uma perspectiva mais integrada sobre as consequências positivas e negativas da implantação de ações afirmativas nas Universidades. As autoras traçam trajetórias da discussão sobre o tema nos Estados Unidos e no Brasil com base nas referidas unidades de análise. No caso norte-americano, as linhas de pensamento seguidas ao longo da história desse país iniciam-se na unidade de análise 1 (pensamento dicotômico contra ou a favor), caracterizada pela divisão histórica da sociedade branca versus negra. Um segundo momento, vivenciado no presente, trata da valorização da diversidade e integração entre negros e brancos ( $2^{\mathrm{a}}$ unidade de análise: exploração de conceitos de diversidade). Desse modo, nos EUA, a trajetória de pensamento acerca das ações afirmativas se deu da unidade de análise 1 para a unidade 2. Já no Brasil essa ordem é inversa. A princípio, no Brasil adotou-se uma ideologia de mistura de raças, um culto à miscigenação, que caracterizou por algum tempo o país como berço da multiculturalidade ( $2^{\mathrm{a}}$ unidade de análise). No entanto, recentemente, o Brasil vem sendo palco para o caminho da distinção étnico-racial ( $1^{\mathrm{a}}$ unidade de análise), que consiste na reavaliação do conceito anterior de "mistura de raças", que deixou para trás marcas do etnocídio presente em todo o processo brasileiro de miscigenação. Assim, no Brasil, as linhas de pensamento vão de 2 para 1 . Nesse sentido, o estudo de Htun (2004) confirma e explora muito bem essa tendência assumida no caso brasileiro. A unidade 3 (reflexões dialéticas) é uma tendência futura, mas ainda bastante incipiente, que implicaria o avanço das discussões das linhas anteriores de pensamento (Guarnieri \& Melo-Silva, 2007).

Entre os programas de Cotas implementados no Brasil, há uma grande variedade de critérios para definição dos cotistas (Guarnieri, 2008). Alguns dos critérios mais utilizados são: étnicos (voltados para os povos indígenas), raciais (relacionados à afro-descendência), étnico-raciais (para afro-descendentes e indígenas), sociais (para egressos da rede pública e/ou avaliados de acordo com a renda familiar), regionais (prioridade de ingresso a estudantes da região da universidade em questão). Importante ressaltar que o critério racial no Brasil assume uma forma diferente da que assume o modelo norte-americano (Munanga, 2004). No caso norte-americano prioriza-se a influência genética e estrutural fundamentada na composição da árvore genealógica do indivíduo. No caso brasileiro, a ênfase é dada à afro-descendência e centra-se em estigmas sociais observáveis fenotipicamente, capazes de justificar práticas discriminatórias.

No Brasil já existe um número considerável de Instituições de Ensino Superior (IES) que introduziram sistemas de Cotas em seus exames de admissão. Alguns órgãos vêm realizando mapeamentos importantes sobre esse cenário. O Laboratório de Políticas Públicas (LPP) (Rio de Janeiro, 2006) e o Programa Políticas da Cor (PPCor) (Rio de Janeiro, 2010), por exemplo, são órgãos criados pela Reitoria da Universidade Estadual do Rio de Janeiro (UERJ), que vêm realizando levantamentos periódicos sobre esses programas de ações afirmativas no Ensino Superior brasileiro, cujas informações estão disponíveis via internet no site: www.politicasdacor.net. Dados desses levantamentos apontam que, se em 2005 havia 14 IES com programas de Cotas em funcionamento (Guarnieri, 2008), em 2006 esse número aumentou para 43 IES, das quais 28 eram públicas $(07$ federais, 19 estaduais e 02 municipais) e 15 eram particulares. Já em 2008, a listagem apresentou modificações: continha 51 IES, todas públicas ( 28 federais, 21 estaduais e 02 municipais). Mais recentemente, em setembro de 2010, o número de IES com Cotas aumentou para 83, todas públicas ( 35 federais, 43 estaduais e 05 municipais). $\mathrm{O}$ aumento significativo no número de IES públicas, com programas de Cotas e a extinção de programas em IES particulares no período de 2006 a 2008 evidenciam a importância do debate sobre as ações afirmativas na sociedade, visando a gerar política pública e na academia objetivando produzir conhecimento. Assim sendo, reafirma-se a relevância de estudos direcionados para 
investigação dessa temática no cenário brasileiro que incluam a implantação, o acompanhamento e a avaliação da eficácia de tais medidas.

Em se tratando de Políticas Públicas, o Poder Legislativo Brasileiro vem realizando tentativas para normatizar a prática de implementação de programas de ações afirmativas no âmbito das universidades por meio de Projetos de Lei. Nesse sentido, o Rio de Janeiro foi o primeiro Estado brasileiro a legislar um programa de cotas, fundamentado em leis estaduais (1.258/2000 e 3.524/2000). O Projeto de Lei Estadual do Rio de Janeiro de $\mathrm{n}^{\circ} 1.258 / 2000$ prevê a reserva de $50 \%$ das vagas em universidade pública para alunos egressos da rede pública de Ensino Fundamental e Médio. A Lei ${ }^{\circ}$ 3.524/2000 (que recebeu alterações) concebe a reserva de $40 \%$ das vagas da Universidade Estadual do Rio de Janeiro (UERJ) e da Universidade Estadual do Norte Fluminense (UENF) para alunos de descendência afro ou indígena. Trata-se de dois critérios (social e étnicorracial) independentes entre si.

No âmbito federal, em 2004 foi elaborado o PL 3627/04, de autoria do poder executivo (Tarso Genro), um dos primeiros Projetos de Lei (PL) que utilizaram critério misto integrado (étnico-racial e social) para instituir as Cotas universitárias nas IES. Instituía-se a reserva de vagas para estudantes negros e índios que haviam cursado o nível médio totalmente em escolas públicas (Projeto de Lei n. 3627, 2004). Mais recentemente, em setembro de 2008, a Câmara dos deputados aprovou o Projeto de Lei 3913/08, da senadora Ideli Salvatti (PT$\mathrm{SC}$ ), que reserva metade das vagas em universidades públicas federais, vinculadas ao Ministério da Educação, adotando como único critério a variável social, apenas aos alunos que cursaram todo o ensino médio em escolas públicas (Araújo, 2008). Incluem-se nesse projeto não só as universidades públicas, como instituído pelo PL 3627/04, mas também as escolas técnicas.

Além dos citados, outros projetos de lei foram elaborados, uns mais aceitos do que outros, dependendo dos critérios utilizados para definição dos beneficiários cotistas. Critérios exclusivamente étnico-raciais são malvistos em uma sociedade que prima pela indistinção de cor/etnia. No Brasil, os modelos mais bem aceitos são os que, para definir os beneficiários dos programas, utilizam critérios mistos, levando em consideração a variável étnico-racial associada a outras variáveis como, por exemplo, a condição socioeconômica e mérito ou desempenho mínimo do candidato em exames de admissão.

Revela-se, portanto, a necessidade de fiscalização e acompanhamento desses programas, para que o conceito de ação afirmativa não se distorça diante de interesses políticos e institucionais. Além disso, há necessidade de acompanhar o processo de inserção e permanência dos alunos cotistas na universidade, de tal modo que lhes sejam assegurados permanência e acolhimento institucional. É preciso, também, verificar quais são as principais dificuldades relacionadas à formação escolar desses alunos; as decorrentes de restrições financeiras e as questões relativas às relações étnicoraciais e sociais. Outro aspecto a ser considerado diz respeito à aceitação desses alunos no meio universitário. Em muitas situações observa-se certo constrangimento envolvendo a entrada do aluno cotista na Universidade. A ausência de crítica sobre os métodos de avaliação para o ingresso na carreira em cursos e universidades de prestígio somada à dificuldade em compreender o significado de ações afirmativas em uma sociedade democrática configura um embate que tende a rivalizar alunos cotistas e não-cotistas e a dividir opiniões. $\mathrm{Ou}$ seja, alunos não-cotistas reagem negativamente às novas medidas de inserção, percebidas como prejuízo a sua condição de não-beneficiários. Julgam-se desprestigiados com essas medidas e consideram os beneficiários cotistas como seus adversários na busca uma vaga na universidade. De um lado estão os alunos não-cotistas e demais membros da universidade acostumados ao vestibular tradicional que privilegia os estudantes das melhores escolas de ensino médio e fundamental e com maiores oportunidades também em termos de capital cultural. Do outro lado estão os alunos cotistas, atuais beneficiários desses programas de inclusão, buscando construir as próprias bases para uma identidade que se efetive no meio universitário e social.

Muitos estudantes que poderiam ser beneficiados com um programa de Cotas tendem a discordar de tal alternativa, temendo serem hostilizados no meio universitário. Ser bem acolhido ou não vai depender das estratégias adotadas pelas Instituições de Ensino. É preciso lembrar que ações afirmativas enfrentam resistências entre aqueles que já assimilaram a ideologia da valorização do mérito individual e, ambos, alunos cotistas e não-cotistas, compartilham da mesma ideologia. O ingresso na universidade por meio de Cotas pode ser entendido como um atestado público de incapacidade e demérito. Os achados de Guarnieri (2008) apontam nessa direção.

Dessa forma, a reivindicação por Cotas interfere diretamente sobre os exames vestibulares até então compreendidos em termos exclusivamente meritocráticos, ou seja, cujos resultados dependem unicamente de esforços pessoais. É senso-comum afirmar que estudantes detentores de maior capital econômico e cultural são privilegiados notavelmente por esses exames. Nesse sentido, Whitaker e Onofre (2006) denominam o "fenômeno dos vestibulares" como um dos rituais de passagem mais importantes que marcam o fim da adolescência e introduzem parte da juventude nos espaços privilegiados da universidade. Assim, os rigorosos 
processos dessa seleção, aliados a um Ensino Médio muitas vezes ineficaz, criaram uma demanda crescente por cursos pré-vestibulares (os chamados cursinhos), os quais têm finalidade de preparar os candidatos para êxito nos exames. Dessa forma, os estudantes interessados em ingressar em uma carreira universitária recorrem à complementação dos estudos nesses cursos. Tradicionalmente são cursos ministrados em instituições particulares, os quais condensam o conteúdo programático dos níveis de ensinos anteriores e podem ter duração de um ano (extensivo) ou seis meses (semiextensivo). No entanto, além dos cursinhos tradicionais, há também os chamados cursinhos alternativos (também denominados populares ou comunitários), que correspondem a instituições de cunho filantrópico com objetivo de preparar estudantes em situação de desvantagem socioeconômica para a realização de exames vestibulares.

Assim sendo, o presente estudo objetiva investigar como a reserva de vagas na universidade é percebida pelo grupo de agentes sociais diretamente atingidos por esse tipo de medida, ou seja, estudantes que buscam uma vaga no Ensino Superior. Na opinião desses jovens, quais seriam as repercussões das políticas de Cotas a curto, médio e longo prazo? Há implicações dessas medidas sobre as expectativas profissionais desses adolescentes?

Assim, investigar a opinião de vestibulandos de cursos tradicionais e alternativos sobre o vestibular é relevante para o levantamento das perspectivas dos principais interessados nessa questão. Este estudo visa a contribuir com a produção do conhecimento nas áreas da Psicologia e da Educação, em especial da Psicologia Social, Educacional e da Orientação Profissional e de Carreira.

O objetivo geral desta pesquisa consiste em investigar as opiniões de estudantes em situação de vestibular sobre o sistema de reserva de vagas ou medidas de ação afirmativa no Ensino Superior. Espera-se com este estudo contribuir para o debate sobre Cotas universitárias, que é recente no Brasil, fornecendo dados atuais diante de uma amostragem de estudantes que recebem diretamente a influência dessas medidas governamentais.

\section{Método}

\section{Participantes}

Participaram voluntariamente 107 vestibulandos matriculados em cursos pré-vestibulares, distribuídos em dois subgrupos: um composto por cursos prévestibulares alternativos (populares e comunitários), identificados como Grupo A (GA) e outro formado por cursos pré-vestibulares tradicionais (particulares), identificados como Grupo B (GB). A configuração dos grupos encontra-se na Tabela 1.
Tabela 1. Distribuição dos participantes dos grupos A e B, tendo a modalidade dos cursos como variável central

\begin{tabular}{lcccccc}
\hline & \multicolumn{2}{c}{ GA } & \multicolumn{2}{c}{ GB } & \multicolumn{2}{c}{ TOTAL } \\
\cline { 2 - 7 } & $\mathrm{n}$ & $\%$ & $\mathrm{n}$ & $\%$ & $\mathrm{~N}$ & $\%$ \\
\hline Moças & 32 & 60,4 & 33 & 61 & 65 & 60,8 \\
\hline Rapazes & 21 & 39,6 & 21 & 39 & 42 & 39,2 \\
\hline TOTAL & 53 & 100 & 54 & 100 & 107 & 100 \\
\hline
\end{tabular}

$\mathrm{O}$ acesso aos participantes deu-se mediante contato com cursos pré-vestibulares, tradicionais e alternativos, pois nesses cursos concentram-se os estudantes que aspiram à universidade. Descrevem-se a seguir informações sobre o perfil dos participantes deste estudo (Tabela 2).

Tabela 2. Distribuição dos participantes do Grupo A e do Grupo B, de acordo com a autodenominação étnico-racial

\begin{tabular}{lcccccc}
\hline & \multicolumn{2}{c}{ GA } & \multicolumn{2}{c}{ GB } & \multicolumn{2}{c}{ TOTAL } \\
\cline { 2 - 7 } & $\mathrm{n}$ & $\%$ & $\mathrm{n}$ & $\%$ & $\mathrm{~N}$ & $\%$ \\
\hline Branco & 31 & 58,5 & 49 & 90,7 & 80 & 74,8 \\
\hline Pardo & 16 & 30,2 & 4 & 7,4 & 20 & 18,7 \\
\hline Preto & 4 & 7,6 & 0 & 0 & 4 & 3,7 \\
\hline Amarelo & 0 & 0 & 1 & 1,8 & 1 & 0,93 \\
\hline Indígena & 1 & 1,9 & 0 & 0 & 1 & 0,93 \\
\hline S/D & 1 & 1,8 & 0 & 0 & 1 & 0,93 \\
\hline TOTAL & 53 & 100 & 54 & 100 & 107 & 100 \\
\hline
\end{tabular}

Com relação à autodenominação étnico-racial, como mostra a Tabela 2, tanto no GA quanto no GB há prevalência de adolescentes autodenominados brancos. No entanto, no grupo A pouco mais da metade dos alunos se define como "branco" (58,5\%). No grupo B, a grande maioria dos participantes se autodenomina branca $(90,7 \%)$. Observa-se que a baixa porcentagem de estudantes negros (pretos e pardos) e indígenas nos cursos preparatórios reforça a reprodução das desigualdades educacionais e socioeconômicas que mantêm essas minorias afastadas de níveis superiores de ensino.

A natureza administrativa da escola de procedência dos participantes é um indicador de nível socioeconômico dos participantes. Nos cursos pré-vestibulares alternativos (GA), a grande maioria recebeu formação do Ensino Fundamental (EF) da rede pública $(85 \%$; $\mathrm{n}=$ $45)$ e apenas uma minoria $(15 \% ; n=8)$ cursou na rede particular. No Ensino Médio, essa tendência se acentua: $94 \%$ do GA $(\mathrm{n}=50)$ cursaram em escola pública e apenas $4 \%(n=3)$ cursaram em rede particular. 
Por sua vez, os alunos dos cursinhos particulares (GB) receberam a Educação Fundamental principalmente no ensino privado $(68 \% ; \mathrm{n}=37)$, ainda que uma parcela tenha cursado o ensino público $(30 \% ; n=16)$. No Ensino Médio (EM), essa tendência também se acentua, de modo que $89 \%$ de GB $(n=48)$ dos alunos completaram esse nível de ensino em escola particular e apenas $9 \%(n=5)$ estudaram na rede pública. Os dados indicam uma tendência de que as chances de um aluno do EM público ter estudado no EF público são maiores do que se ele o tivesse realizado na rede particular. $\mathrm{O}$ mesmo raciocínio se aplica em relação aos que estudaram na rede particular de ensino, no sentido inverso.

Sobre a experiência prévia com vestibulares (Tabela 3), prevalecem no GA os estudantes que ainda não prestaram qualquer exame vestibular $(60,4 \% ; n=32)$, sendo que no $\mathrm{GB}$ a grande maioria $(92,6 \% ; \mathrm{n}=50)$ já havia passado por essa experiência. Ou seja, o GB foi mais exposto à experiência de aprendizado tanto com relação a aspectos formais dos exames seletivos quanto a aspectos mais subjetivos, que envolvem a situação de fracasso frente ao vestibular.

Tabela 3. Distribuição das respostas dadas sobre a experiência anterior com relação a vestibulares e o ingresso anterior em instituições de Ensino Superior

\begin{tabular}{l|c|c|c|c|c|c|c|c}
\hline \multirow{2}{*}{} & \multicolumn{4}{|c|}{ GRUPO A } & \multicolumn{4}{c}{ GRUPO B } \\
\cline { 2 - 11 } & \multicolumn{2}{|c|}{ Sim } & \multicolumn{2}{c|}{ Não } & \multicolumn{2}{c}{ Sim } & \multicolumn{2}{c}{ Não } \\
\cline { 2 - 10 } & $\mathrm{n}$ & $\%$ & $\mathrm{n}$ & $\%$ & $\mathrm{n}$ & $\%$ & $\mathrm{~N}$ & $\%$ \\
\hline Já prestou vestibular & 21 & 39,6 & 32 & 60,4 & 50 & 92,6 & 4 & 7,4 \\
\hline Já iniciou alguma faculdade? & 0 & 0 & 53 & 100 & 3 & 5,5 & 51 & 94,4 \\
\hline
\end{tabular}

Dentre os 107 estudantes, seis deles foram entrevistados objetivando o aprofundamento de informações. Foram entrevistados três participantes do Grupo A (Ana, Alceu e Antônio) e três do Grupo B (Bruna, Bianca e Breno), com faixa etária entre 17 e 19 anos de idade. Todos autodenominados brancos. Note-se que a identificação do grupo de pertença dos participantes (A ou B) é feita pela primeira letra do nome fictício.

Importante ressaltar que a composição seguiu alguns critérios. Além da disponibilidade do estudante para participar da entrevista, outro critério utilizado para seleção dos entrevistados foi o preenchimento da sessão "comentários", ao final do questionário. Tal critério estabeleceu-se pelo fato de sugerir interesse dos participantes em discorrer mais sobre o tema.

\section{Instrumentos}

1. Questionário COTAS - utilizado na $1^{\mathrm{a}}$ etapa do estudo. Divide-se em três partes. A primeira corresponde às informações sociodemográficas - dados do participante e de seus pais ou responsáveis, no que se refere à escolaridade, atividade profissional e autodenominação étnico-racial. A segunda parte do instrumento corresponde à opinião dos participantes sobre conteúdos específicos (Vestibular, Cotas Universitárias, Medidas Governamentais de acesso ao Ensino Superior e Questão Racial). A terceira parte corresponde à avaliação do questionário, com uma questão aberta para exposição de comentários, além de informações pessoais para localização e estabelecimento de contato posterior com os participantes para fins do próprio estudo.
2. Entrevista: as entrevistas foram individuais, semiestruturadas, cujos temas centrais referiam-se à opinião pessoal sobre as Cotas e às perspectivas sobre o futuro. Todas as entrevistas foram gravadas com o consentimento dos entrevistados. Outros temas foram abordados na medida em que emergiam espontaneamente nos relatos dos entrevistados.

\section{Procedimentos}

O presente estudo foi submetido ao Comitê de Ética em Pesquisa (CEP) da Instituição de Ensino Superior na qual o Mestrado foi realizado, sendo analisado e aprovado. A coleta dos dados foi realizada em duas etapas. A primeira consistiu na aplicação coletiva do Questionário COTAS nos próprios cursinhos ou mediante entrega do material em mãos aos vestibulandos para serem respondidos em suas residências. A segunda etapa correspondeu à realização de entrevistas individuais semiestruturadas, em situação face-a-face, com seis participantes da etapa anterior. Os procedimentos específicos de cada etapa serão descritos detalhadamente a seguir.

Na primeira etapa, cinco cursos pré-vestibulares se disponibilizaram a participar do presente estudo. Quatro deles localizam-se na cidade sede do Programa de Pós-Graduação e um em outra cidade da região. $\mathrm{O}$ contato com as instituições participantes foi realizado inicialmente por telefone, momento em que as escolas eram informadas acerca dos objetivos da pesquisa e decidia se participaria ou não. Com a aceitação em participar da pesquisa, era agendado um horário com 
o coordenador responsável para apresentação dos seguintes documentos: instrumento de coleta, termo de consentimento livre e esclarecido - os quais foram entregues aos estudantes - e uma autorização a ser assinada pelo diretor ou coordenador responsável pelo cursinho, para incorporar a documentação submetida ao Comitê de Ética em Pesquisa da Universidade. Com esse mesmo responsável era realizada uma entrevista com a finalidade de esclarecer possíveis dúvidas acerca da pesquisa e de conhecer mais sobre a Escola, sua estrutura e funcionamento, bem como obter dados gerais sobre os alunos. Durante essa entrevista foram acordadas estratégias para a aplicação e recolha do instrumento, negociadas entre a pesquisadora e os coordenadores de cada curso preparatório em função do objetivo da pesquisa e da disposição estrutural e de funcionamento das instituições de ensino.

$\mathrm{Na}$ segunda etapa, foram realizadas entrevistas individuais com seis participantes, sendo três do Grupo A e três do Grupo B. Inicialmente definiram-se os critérios "autodenominação" (branco ou preto/pardo) e opinião sobre Cotas (favoráveis ou contrários). Como a quantidade de alunos autodenominados negros e que aceitaram participar do estudo foi insuficiente, os critérios foram modificados para seleção dos entrevistados. Definiu-se, então: (1) disponibilidade do estudante para participar da entrevista e (2) preenchimento da sessão "comentários", ao final do questionário, com conteúdos que sugeriram reflexões relevantes para a investigação. Esse segundo critério foi estabelecido pelo fato de sinalizar ao investigador o interesse dos participantes em discorrer mais sobre o tema. Os convites para a entrevista foram feitos por meio de contato telefônico, no qual a pesquisadora localizava o jovem, verificava se havia interesse e disponibilidade do mesmo em participar da entrevista. Em caso afirmativo, estabelecia-se um local, data e hora que correspondessem às possibilidades da dupla (entrevistador/entrevistado). Dos convites realizados, sete foram descartados, pois os participantes recusaramse a dar entrevista, alegando: indisponibilidade de tempo $(n=3)$, falta de interesse sobre o assunto $(n=1)$ ou não alegaram qualquer motivo $(n=3)$. Ao final foram entrevistados efetivamente seis participantes, sendo três do Grupo A e os outros três do Grupo B. As entrevistas duraram em média 20 minutos, sendo que a mais longa teve duração de 40 minutos (Bruno, Grupo B) e a mais curta, 15 minutos (Bianca, Grupo B). Todas foram gravadas com o consentimento dos entrevistados. O eixo central da entrevista consistiu na opinião dos participantes sobre as Cotas universitárias. Buscou-se investigar as temáticas que mais se destacavam nas falas dos entrevistados (conteúdos afetivos, cognitivos e ideológicos). Temas pertinentes - como, por exemplo, o vestibular e o preconceito racial - ao serem abordados pelos entrevistados, eram explorados pela pesquisadora durante a entrevista.

O corpus de análise foi constituído pelas respostas dadas pelos participantes $(n=107)$ à questão sobre os melhores critérios que poderiam ser utilizados por Programas de Cotas Universitárias e o conteúdo das entrevistas individuais $(n=6)$. A análise de conteúdo foi feita com base em Bardin (1977). Assim, os dados foram organizados em quatro unidades de análise: (1) Argumento favorável às Cotas Universitárias; (2) Preocupações com o impacto negativo da introdução dos Programas de Cotas; (3) O viés socioeconômico: atitudes frente ao vestibular e à escolha de carreira e (4) Trajetórias e Expectativas.

Considerando que o acesso à universidade constitui um fenômeno do universo da Psicologia Vocacional e da Intervenção de Carreira, considerou-se a Teoria Social Cognitiva de Carreira (TSCC) apropriada para compor o referencial teórico-metodológico deste estudo. A perspectiva sociocognitiva centra-se na interação sistêmica entre pessoa, contexto e comportamento, na qual esses três elementos se influenciam mutuamente. Essa relação de tripla dependência é denominada reciprocidade triádica, isto é, a conduta, os fatores pessoais (cognitivos ou de outra natureza) e os fatores ambientais atuam como determinantes interativos. Nesse referencial teórico a pessoa é agente do seu desenvolvimento e intencionalmente responsável perante seu destino individual e o mundo, cujos recursos monitoriza, no sentido de operar mudanças e de geri-las no seu sistema individual e ambiental.

Como afirmam Vieira e Coimbra (2006), "tal perspectiva não minimiza a importância das características objectivas do contexto, mas chama a atenção para o papel activo do indivíduo enquanto intérprete do seu contexto, isto é, a importância incontornável do significado pessoalmente construído" (p. 37), ou seja, subjetivo que se traduz na prática. Assim, a agência pessoal do indivíduo, ou seja, as "variáveis sociocognitivas autorreferentes", é definida pelos seguintes constructos: autoeficácia, expectativas de resultados e objetivos alcançados. A autoeficácia, de acordo com Bandura (1977), corresponde a crenças que o indivíduo possui sobre si mesmo, sobre "sua capacidade para executar cursos de acção requeridos para alcançar determinados tipos de desempenhos" (p. 30). Já a expectativa de resultados é definida por Lent, Brown e Hackett (1999, citado por Vieira \& Coimbra, 2006, p. 34) como as "consequências antecipadas frente a esforços comportamentais". Por fim, os objetivos das ações empreendidas correspondem à determinação do sujeito para se entregar a determinada atividade, buscando alcançar sucesso futuro. Para fins deste estudo, a Teoria Social 
Cognitiva de Carreira foi considerada apropriada para compreender as "perspectivas de estudantes em situação de vestibular sobre as Cotas Universitárias", uma vez que os jovens apresentam como crenças de autoeficácia a capacidade para passar no vestibular, têm como expectativas de resultados passarem no vestibular e, como objetivo, acessarem a carreira escolhida. Para tal empreendem ações com vista a alcançarem os resultados e assim ingressar em uma universidade. Para alcançar sucesso nesse processo, a tríade pessoa, contexto e comportamento precisa ser considerada, como mostra a Figura 1, que apresenta o modelo de predição da Escolha Vocacional de Lent (Lent, Brown, \& Hackett, 1994), com inserções em negrito, feitas pelos autores, objetivando explicitar as aplicações da TSCC para a compreensão do objeto deste estudo.

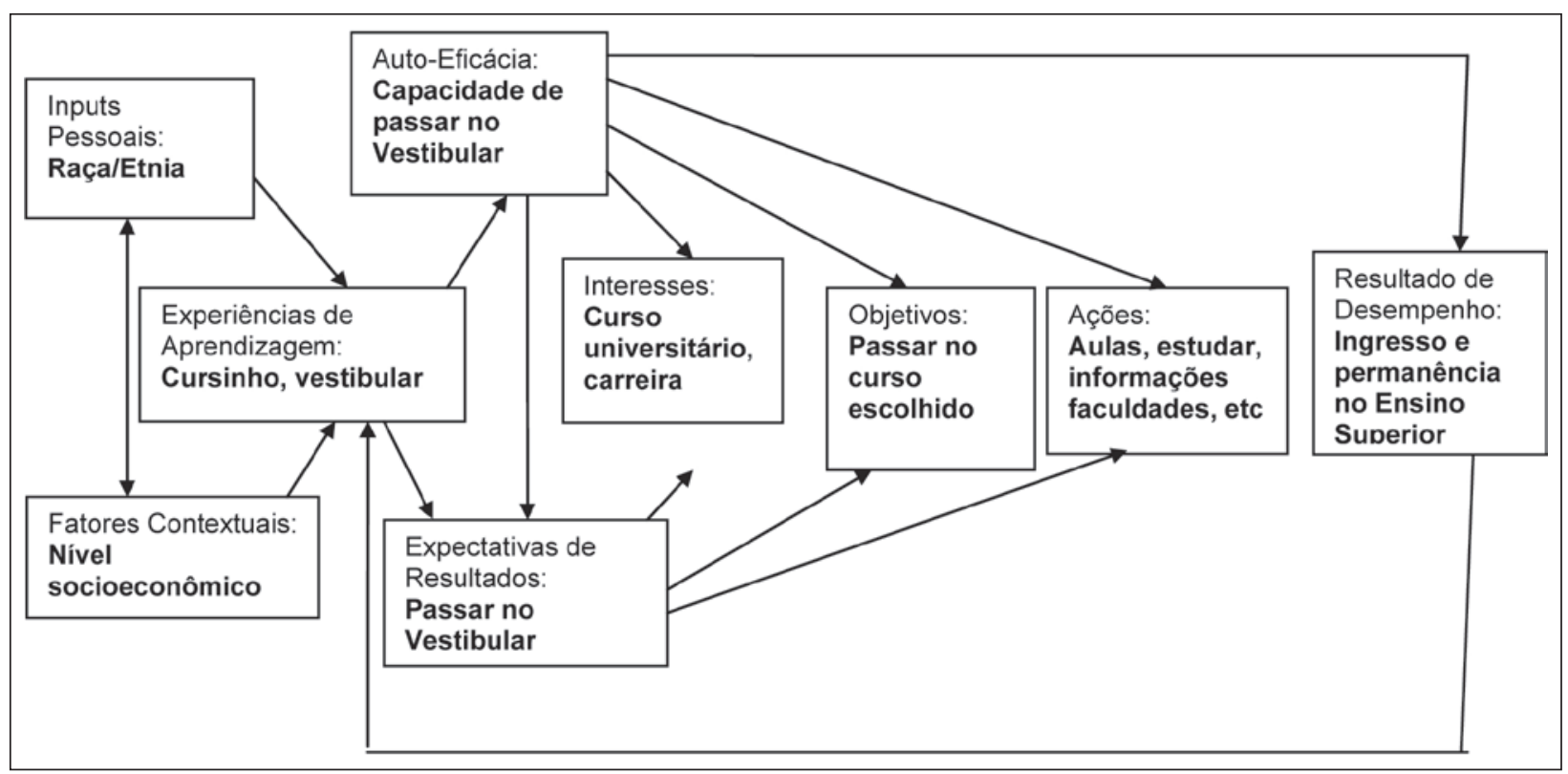

Figura 1. Modelo de Predição da Escolha Vocacional de Lent, Brown e Hackett (1994), fundamentados na Teoria Social Cognitiva de Carreira (TSCC), com inserções em negrito, feitas pelos autores, relativas aos objetos do presente estudo

\section{Resultados}

Com relação às Cotas Universitárias, os critérios mais bem aceitos entre os estudantes foram aqueles que $(39,6 \%)$, seguido pela afirmação de que não deveria haver Cotas $(36,9 \%)$, como mostra a Tabela 4. estabelecem Cotas para alunos egressos da rede pública

Tabela 4. Questão sobre os melhores critérios que poderiam ser utilizados por Programas de Cotas Universitárias

\begin{tabular}{|c|c|c|c|c|c|c|c|c|}
\hline & \multicolumn{4}{|c|}{ Sexo } & \multicolumn{4}{|c|}{ Cursinho } \\
\hline & \multicolumn{2}{|c|}{ q } & \multicolumn{2}{|c|}{$\hat{\sigma}$} & \multicolumn{2}{|c|}{ Grupo A } & \multicolumn{2}{|c|}{ Grupo B } \\
\hline & $\mathrm{n}$ & $\%$ & $\mathrm{n}$ & $\%$ & $\mathrm{n}$ & $\%$ & $\mathrm{~N}$ & $\%$ \\
\hline Só para Negros e Indígenas & 1 & 1,6 & 1 & 2,4 & 1 & 1,9 & 1 & 1,9 \\
\hline Só para alunos de escola pública & 27 & 42,2 & 15 & 35,7 & 20 & 37,7 & 22 & 41,5 \\
\hline Negros, Indígenas e alunos de escola pública & 10 & 15,6 & 13 & 31 & 20 & 37,7 & 3 & 5,7 \\
\hline Não deveria haver Cotas & 26 & 40,6 & 13 & 31 & 12 & 22,6 & 27 & 50,9 \\
\hline TOTAL & 64 & 100 & 42 & 100 & 53 & 100 & 53 & 100 \\
\hline
\end{tabular}


Quando considerado o sexo dos participantes, entre as moças a tendência apresentada anteriormente se confirma e se intensifica, sendo que $42,2 \%$ respondem "só para alunos de escola pública" e 40,6\% opinam que "não deveria haver Cotas". Já entre os rapazes, outro critério também foi considerado: enquanto $35,7 \%$ respondem que as Cotas deveriam ser só para alunos de escola pública, $31 \%$ deles concordam que o melhor seria reserva de vagas para negros, indígenas e alunos de escola pública e outros $31 \%$ afirmam que não deveria haver Cotas. Há, portanto, entre os rapazes, maior aceitação das Cotas e, especificamente, do critério misto, que reúne critério social e étnico-racial. Importante ressaltar que esse tipo de critério tem sido cada vez mais utilizado pelos programas de Cotas em funcionamento e foi incorporado à Lei Federal aprovada recentemente pela Câmara dos deputados em setembro de 2008 (Araújo, 2008).

Com relação ao tipo de cursinho houve um movimento interessante. No grupo de cursinhos alternativos (GA) as opiniões dos participantes dividiram-se: $37,7 \%$ respondem que o melhor seria Cotas para alunos de escola pública e outros 37,7\% apoiam as Cotas desde que se direcionem a "negros, indígenas e alunos de escola pública", enquanto $22,6 \%$ declararam que não deveria haver Cotas. No grupo de cursinhos particulares (GB) seguiu-se a tendência do total de participantes, com aumento percentual sobre a afirmação de que não deveria haver Cotas $-50,9 \%$, seguida pela aceitação do critério "só aluno de escola pública" (41,5\%).

Foram recordados episódios das entrevistas que pontuam com maior objetividade os argumentos e perspectivas dos estudantes entrevistados. Com base na Análise de Conteúdo de Bardin (1977), os referidos recortes foram organizados em quatro unidades de análise: (1) Argumento favorável às Cotas Universitárias, (2) Preocupações com o impacto negativo da introdução dos Programas de Cotas, (3) O viés socioeconômico: Atitudes frente ao vestibular e à escolha de carreira $\mathrm{e}$ (4) Trajetórias e Expectativas. A seleção do conteúdo visa a focalizar a perspectiva de estudantes que estão passando por uma situação semelhante (todos às portas do vestibular), traduzindo-se numa fonte rica para a compreensão do universo desses jovens.

\section{Argumento favorável às Cotas Universitárias}

Um dos poucos argumentos favoráveis à adoção de Cotas aponta que as mesmas representam uma forma de intervenção direta sobre o preconceito racial. Argumentou-se que, apesar de se tratar de uma medida emergencial bastante agressiva de inserção (étnicoracial e social), acredita-se que a mesma assim se justifique por ser uma tentativa de interferência direta sobre um dos espaços de propagação do preconceito racial, representado pelo Ensino Superior. Uma participante diz: "Por um lado eu sou a favor. Porque eu vejo que se não fizer isso, não vai mudar nunca, porque o governo não vai mudar de lá de baixo [referindo-se aos níveis de ensino que antecedem o ensino superior]. Eu sou meio pessimista quanto a isso..." (Bruna). ${ }^{2} \mathrm{~A}$ fala dessa participante explicita a percepção de que há questões nas quais a realidade só pode ser modificada com intervenção direta do Governo.

\section{Preocupações com o impacto negativo da introdução dos Programas de Cotas}

Em todas as entrevistas foi possível observar a existência de preocupações advindas de crenças sobre a implementação de Programas de Cotas. Seguem algumas das principais questões abordadas pelos entrevistados. A primeira delas relaciona-se à crença no impacto negativo das Cotas sobre o desempenho e sobre o revanchismo entre os candidatos cotistas e não-cotistas.

O processo seletivo do vestibular tradicional, afirmam eles, instiga o mérito conquistado pelo esforço individual. Em contrapartida, a reserva de vagas, ao facilitar o ingresso do aluno, irá desestimulá-lo nos estudos "ao que vem com facilidade, ninguém dá valor", além de promover o revanchismo entre alunos que foram e os que não foram beneficiados pelo sistema de Cotas. Acredita-se, assim, que a entrada de estudantes cotistas favorecerá a queda de qualidade nesse nível de ensino e desestimulará o empenho dos cotistas dentro das universidades, como demonstram as falas a seguir:

“A escola pública já está ruim, agora colocar aqueles
alunos ruins para ir numa faculdade [pública], vai
estragar o ensino na faculdade também. Eu acho que
não é por aí não" (Alceu).
"Mas vamos supor, desses $50 \%$ de escola pública que
entrassem numa USP [retoma critério do projeto de Lei
$3627 / 04] . .$. Por exemplo, eu entrei na USP essa semana
e é matéria, matemática forte, já... Eu acho que os de
escola pública não seriam capazes de acompanhar,
ter o mesmo aproveitamento dos de escola particular
... Ou seja, a universidade poderia cair no seu rendi-
mento." (Breno)
"Cotas não deveriam existir. Por quê? Porque eu acho
que uma pessoa deve entrar pela capacidade que ela
deve ter. Porque uma coisa que venha fácil, que venha
com facilidade, a gente não dá valor" (Alceu).
"Só que ai eu não consegui passar numa escola pú-
blica. Aí a gente acaba perdendo vaga para pessoas
que estudaram [no EM público]... a gente acaba se
prejudicando" (Bianca).

Nesses trechos, há evidência de uma preocupação comum no que diz respeito às Cotas, mas que resulta da falta de informações sobre essa política de ação afir- 
mativa. Ainda que haja reservas de vagas, há também a nota de corte que, se não alcançada, impede o aluno de ingressar na Universidade por meio de reserva de vagas. Se não houver demanda para as vagas reservadas, as mesmas serão reintegradas ao sistema tradicional de distribuição.

Assim, as Cotas são percebidas como prejudiciais tanto para alunos que não se beneficiarão quanto para os próprios cotistas. Aqueles por se prejudicarem pelo acirramento da disputa de vagas e estes por não valorizarem essa oportunidade (por razões ideológicas), já que foi conquistada com "menos esforço", como mostram as falas. Nesse sentido, nota-se a força do discurso ideológico que culpabiliza o indivíduo (no caso, o estudante) por problemas macroestruturais como, por exemplo, a escassez de vagas (o que acirra a concorrência) e inconsistências no tipo de avaliação proposta pelo vestibular e seu significado para o desempenho dos selecionados no âmbito universitário.

$\mathrm{Na}$ medida em que a seleção realizada por vestibulares tradicionais recebe influência de variáveis como o capital cultural e econômico, é importante que seja desnaturalizada sua definição fundamentada exclusivamente no mérito e esforços individuais. É importante ressaltar que o desempenho nos exames seletivos recebe influência de variáveis microestruturais (por exemplo, o esforço e interesse do aluno) e macroestruturais (oportunidades de ingresso e situação da educação brasileira em seus diversos níveis). Tal concepção, ao integrar o sucesso no vestibular a "aquisições coletivamente realizadas", integra melhor uma realidade composta por sujeitos e contextos, ambos passíveis de intervenção e aperfeiçoamento.

A segunda preocupação que mais apareceu no discurso dos estudantes refere-se à autodenominação como fator fomentador do racismo no Brasil. Algumas crenças sobre as consequências do critério da autodenominação étnico-racial são apontadas nas falas a seguir. "Até porque todo mundo não fala que o Brasil é miscigenado? Então como se diferencia um índio de um negro? Todo mundo tem o mesmo tipo de sangue" (Bruna) / "Não concordo, assim, em diferenciar o ser humano em raças. Raça é humana" (Breno). Há, nesses trechos, a reprodução do discurso apaziguador da multirracialidade brasileira.

Coloca-se também em questão quem deve assumir a responsabilidade pelos prejuízos históricos do período de escravidão.

Por um lado ela beneficia negros e indígenas, queira ou não, que antigamente já foram muito discriminados, marginalizados pela sociedade... e até hoje isso se reflete. Só que, por um lado, também pode estar prejudicando pessoas, principalmente as pessoas da classe média, e eu me incluo nessa. (Bianca)
Essa tentativa de nivelar etnicamente o ser humano só faz sentido se for compreendida em sua complexidade, isto é, ao mesmo tempo em que traduz um ideal de compreensão humana, na prática é ainda permeada pela descaracterização cultural e pelo atropelo ou intolerância diante da bagagem cultural de um povo que se difere de modelos hegemônicos de referência cultural.

\section{O viés socioeconômico: atitudes frente ao vestibular e à escolha de carreira}

$\mathrm{O}$ vestibular consiste num marco, um ritual de passagem que tem um peso diferenciado para alunos egressos da rede pública e para os da particular. Assim, com relação à perspectiva dos grupos de participantes GA e GB, pôde-se notar que, com relação ao vestibular, no grupo A, a perspectiva é mais positiva, pois o vestibular é visto como uma oportunidade de mudança de vida, uma forma de ascender socialmente. No Grupo A, o cursinho representa uma ferramenta importante de aprendizagem, que será utilizada para superar a grande barreira no ensino superior de qualidade. Nesse sentido, o vestibular representa mais uma oportunidade de mudança de vida do que uma barreira propriamente dita. Talvez esse fato ajude a entender por que os alunos desse grupo são mais otimistas sobre o exame vestibular. Entre os entrevistados do Grupo A, o interesse por um curso universitário estava relacionado ao status social e a expectativas de melhoria de vida e ascensão social: "É uma chance que vai começar a mudar minha vida. É uma meta minha, que é vencer na vida... Por tudo que minha mãe passou, acho que vale a pena lutar por um sonho" (Alceu). Já quanto à escolha do curso, prevalecem os cursos que oferecem mais oportunidades de ingresso, os menos concorridos e/ou com menor relação candidato/vaga.

No grupo B, o vestibular é percebido como obstáculo para a sequência dos estudos, uma barreira capaz de impedir a concretização de um plano de carreira. Mesmo quanto à escolha de carreira há diferenças nos posicionamentos. No grupo A, a carreira escolhida não é pensada como prioridade em termos de escolha, mas como meio para ingressar no Ensino Superior, na universidade. Ou seja, no Grupo A, a prioridade é o ingresso em si, independentemente das identificações pessoais e profissionais associadas a determinado curso que se pretende seguir. Já no grupo B, a carreira é mais pensada em função das identificações dos alunos com o curso escolhido e com o fazer profissional. $\mathrm{O}$ fato dos participantes do grupo B contarem com serviço de Orientação Profissional oferecido pela escola reforça a ideia de que nesse grupo as escolhas profissionais são prioridade. $\mathrm{O}$ ingresso na universidade acaba sendo 
uma consequência desse processo, e não um fim em si mesmo, como acontece no Grupo A. Para os estudantes de escolas particulares, cursar o Ensino Superior representa o pré-requisito para a inserção futura no mercado de trabalho, como afirma Breno: "Quem não tem uma universidade hoje, tá fora ... A minha mãe não tem universidade, mas ela conseguiu entrar no mercado. Mas a partir da nossa idade, quem não tem universidade, é dificil de se inserir".

A questão da responsabilidade social atrelada ao Ensino Superior foi mencionada por dois entrevistados. Breno e Antonio comentam sobre o papel social que deve ser desempenhado pelos estudantes em sua passagem pela Universidade: "Acho que durante a Universidade eu vou tentar buscar fazer alguma coisa para a comunidade. ... Porque é a sociedade que está pagando para a gente estudar lá. Então eu acho que a Universidade deve dar alguma retribuição para a sociedade" (Breno) I "A pessoa que está na universidade é uma pessoa que tem bom conhecimento, e pra poder ajudar tanto a si mesmo quanto aos outros" (Antônio).

\section{Trajetórias e expectativas}

São apontados os principais empecilhos encontrados no caminho da própria realização pessoal e profissional. Antônio ressalta o obstáculo financeiro, uma das variáveis contextuais, imposto sobre seu desejo de ingressar no Ensino Superior:

eu não tava pensando muito nisso. Tava pensando em arrumar um emprego pra poder ajudar minha mãe, porque é só ela que trabalha em casa. ... Mas aí ela pediu pra eu fazer, que assim ajudaria mais. Eu pensei, e fui na opinião dela ... Eu falava que isso aí era um luxo. (Antônio)

Bruna acrescenta seu relato pessoal de fracassos sucessivos no vestibular como determinante para a mudança de sua escolha do curso de Medicina para o de Administração:

Eu prestava Medicina. Agora mudei para Administração ... Como eu tomei muito pau no vestibular [risos] eu resolvi: meu, vou tentar Administração, sabe, é uma coisa que é muito mais próxima. Já cheguei muito próximo todas às vezes da Medicina, mas nunca passei. E pelo sentimento de frustração resolvi prestar outra coisa. (Bruna)

As variáveis contextuais podem servir também como barreiras percebidas dificultando ou inviabilizando o ingresso no curso universitário, o que leva o jovem a expressar expectativas de resultado negativas. Tais barreiras podem levar tanto à desistência do vestibular, durante o curso universitário e / ou às diversas mudanças de curso, quanto a funcionar como mola propulsora, fator de motivação, desde que haja atitude de superação pessoal e determinação por parte do aluno. As barreiras podem ser objetivas ou subjetivas, o importante é que elas sejam percebidas pelos sujeitos para que possam ser transformadas mediante processos de intervenção.

\section{Considerações finais}

Em síntese, há entre os estudantes preocupações com a implementação das Cotas Universitárias em curto e médio prazo, observa-se a força do viés ideológico ligado à ideia do mérito, tão associado aos vestibulares, que perpassa diferentes níveis sociais e converge para o mito da ineficiência da escola pública nos níveis fundamental e médio e, inversamente, o prestígio no Ensino Superior público. Nesse sentido, foram identificadas algumas preocupações dos estudantes sobre as Cotas Universitárias e sobre o vestibular, que fazem parte de um repertório de representações sociais coerentes com discussões acerca desse tema na sociedade. Outra questão interessante revela-se: há, entre os estudantes, desconhecimento sobre o processo de elaboração, o surgimento e funcionamento de medidas de ação afirmativa. As Cotas aparecem nos discursos de maneira descontextualizada, associadas à atitude do governo de "dar uma ajuda" para os mais "incompetentes", ou vistas como alternativa incompatível à melhoria dos níveis anteriores de ensino.

Há falta de informação fidedigna sobre o tema, o que talvez o torne tão assustador entre os participantes e faça com que os mesmos lancem mão, em seus argumentos, de relatos vivenciais e experiências de terceiros sobre o "desastre" potencial representado pela implementação de Cotas no Ensino Superior brasileiro. No entanto, tais experiências possuem um caráter fantasioso e não condizem com os resultados obtidos pelos programas existentes, nem com o que se tem verificado em pesquisas sistemáticas recentes que acompanham os resultados dessas medidas. Especificamente sobre a questão da queda na qualidade de ensino como resultado da inserção das políticas de Cotas nas universidades, o contra-argumento utilizado pelo LPP é que estudos realizados sobre as IES que possuem sistemas de Cotas revelam que os próprios docentes ( $80 \%$ deles) avaliam o desempenho acadêmico dos alunos cotistas como bom ou muito bom (Santiago, Norberto, \& Rodrigues, 2008). Ainda sobre essa questão, um levantamento preliminar realizado de 2003 a 2007 pelo Educafro (um cursinho popular) indicou que, ao longo da faculdade, os alunos cotistas conseguiram se equiparar aos demais estudantes apesar de terem ingressado na faculdade com nota $40 \%$ inferior à exigida para candidatos não-cotistas (Salme, 2009). Informações como essas, além de contradizerem o mito da incapacidade dos cotistas para acompanharem o ritmo intelectual nas universidades, também sugerem 
questionamentos acerca da capacidade conferida ao exame vestibular de predizer quem está apto ou não a ingressar na universidade.

Em se tratando dos cursos mais concorridos, há alguns dados interessantes. No caso da Universidade Federal da Bahia (UFBA), por exemplo, em $61 \%$ dos cursos mais concorridos, alunos cotistas tiveram um rendimento igual ou superior ao dos não-cotistas, entre os quais estão os tradicionais cursos de Medicina, Direito e Engenharia Civil (Queiroz \& Santos, 2006). Além desses estudos, outros vêm sendo realizados e trazem questionamentos que desnaturalizam a ideia fortemente associada às Cotas como medida incompatível com o sucesso dos seus beneficiários no meio universitário e com a qualidade do ensino em geral (Guimarães, 1997; Htun, 2004; Petruccelli, 2004; Salme, 2009).

Importante ressaltar que a falta de informação consistente sobre o funcionamento efetivo de programas de Cotas Universitárias e o total desconhecimento acerca de outras formas de acesso e permanência no Ensino Superior justificam a implementação de medidas alternativas e, entre elas, as ações afirmativas, de disseminação de informações entre jovens e na comunidade como um todo. Trata-se de um campo que aparece repleto de controvérsias e preocupações, visto que não há clareza, por exemplo, sobre os critérios específicos de seleção (autodenominação étnico-racial, social etc.) ou sobre outros programas de suporte vinculados às Cotas (aulas de reforço, bolsas, acompanhamento de desempenho dos cotistas etc.).

Observou-se que, apesar da ampla expansão de programas de Cotas no Brasil, tanto em Instituições de Ensino Superior de administração pública quanto privada, há a necessidade de regulação dessas medidas e acompanhamento de suas repercussões. Essa é uma tarefa que deve reunir esforços da sociedade civil, da comunidade acadêmica, juntamente com órgãos governamentais para a realização contínua de estudos referentes à efetivação desses programas de modo a cumprirem um padrão mínimo de exigência, que abarquem a prestação de contas sobre os critérios de seleção e mecanismos de manutenção dos novos egressos e suas dificuldades específicas (recursos financeiros, aulas de reforço, entre outras). E ainda de estudos sobre os objetivos dos programas e suas repercussões micro e macroestruturais; sobre desempenho dos cotistas em relação aos demais; levantamento das dificuldades eventuais suscitadas com a adoção dessas medidas (discriminação étnico-racial ou social, estigmas associados ao cotista no espaço intrauniversidade, etc) e espaço para construção de saberes e alternativas para a solução de problemas decorrentes das necessidades de ajustamento das medidas.

$\mathrm{O}$ presente estudo traz contribuições também ao campo da Orientação Profissional e para a Carrei- ra, na medida em que sugere, com base na TSCC, a necessidade de definir estratégias de intervenção que levem em consideração as diferentes demandas emergentes e sejam mais ajustadas ao perfil dos estudantes destinatários das ações afirmativas. Levando-se em consideração as atitudes de ambos os grupos frente ao vestibular, pode-se pensar em formas de intervenção específica para ambos. De acordo com a TSCC, a escolha de carreira deve partir da formação dos objetivos (Vieira \& Coimbra, 2006). Os mesmos surgem como uma resposta que sucede a exploração dos interesses, conduzindo às ações, que por sua vez poderão resultar no desempenho alcançado. No presente estudo tal desempenho está diretamente associado ao ingresso em um curso universitário e, posteriormente, à inserção no mercado de trabalho.

No perfil observado dos estudantes de cursinhos alternativos (Grupo A) há elevadas expectativas de resultados, mas há a necessidade de implementar ações concretas que viabilizem o acesso desses jovens ao Ensino Superior. Esse dado sugere a necessidade de intervenções que propiciem a ativação do comportamento vocacional, tendo em vista a exploração e a informação sobre as carreiras, além de informações gerais sobre vestibulares (bolsas de estudo, isenção de taxa etc.) e sobre os mecanismos de acesso a um curso universitário.

Já entre os estudantes dos cursinhos particulares, há um destaque maior no tocante à preparação efetiva para os exames por parte dos cursinhos. Os mesmos são treinados em situações de simulação de vestibulares, recebem aulas com os conteúdos específicos dos vestibulares mais concorridos. Ou seja, recebem uma preparação mais direcionada para ações que visam aos objetivos. No entanto, suas expectativas de resultado aparecem bastante contaminadas por experiências anteriores de fracasso. Assim, pode-se desenvolver uma intervenção que enfatize o desenvolvimento de variáveis pessoais. De acordo com o modelo de Lent, Brown e Hackett (1994), para intervenção nesse grupo de alunos seria mais ajustado o desenvolvimento de atitudes mais positivas frente a novos desafios, ou seja, com relação à percepção de sua autoeficácia, às próprias experiências de aprendizagem e às expectativas de resultado.

Assim, é importante compreender que o sentido da miscigenação oscila entre dois polos ideológicos bem definidos. Essas relações colorblind (Bollinger, 2003), ou seja, "cegas" para distinção de cor entre povos, de um lado traduzem-se em uma forma evoluída de integrar o ser humano em sua essência e, por outro, encerram-se em uma poderosa estratégia de diluição e enfraquecimento de um povo e sua cultura, já que há relação de poder entre negros e brancos. Dessa forma, o mais forte subjuga o mais fraco, não 
havendo, nesse tipo de "mistura étnico-racial", uma troca, mas sim uma expropriação cultural, baseada na disparidade das relações de poder entre povos fundantes da população brasileira.

No sentido de contribuir para estudos futuros, cumpre destacar que diferentes práticas e linhas investigativas podem ser desenvolvidas nesse domínio, em cenários e contextos diversificados (Guarnieri, 2008), a saber: (1) políticas públicas de acesso e permanência na universidade, (2) avaliação dos programas de Cotas Universitárias, (3) comparação entre diferentes programas de Cotas Universitárias, (4) estudos longitudinais de grupos de alunos cotistas, com acompanhamento durante a universidade e depois no mercado de trabalho, (5) propostas de programas de divulgação na mídia sobre as medidas alternativas de ingresso na universidade, (6) implantação, acompanhamento e avaliação de programas de intervenção em Informação e Orientação Profissional, sobretudo em escolas públicas, entre outras. Todas são linhas investigativas promissoras, atuais e necessárias.

\section{Notas}

1 Este estudo apresenta parte dos dados da Dissertação de Mestrado da primeira autora, orientada pela segunda, com bolsa Fundação de Amparo à Pesquisa no Estrado de São Paulo (FAPESP).

2 Os nomes dos participantes são fictícios e iniciados com a letra que corresponde ao grupo A ou B.

\section{Referências}

Araújo, N. Jr. (2008). Metade das vagas em escolas federais pode ir para cotas. Agência Câmara, Portal Câmara dos Deputados. Acesso em 20 de outubro, 2008, em http://www2.camara.gov. $\mathrm{br} /$ homeagencia/materias.html?pk=\%20126381.

Bandura, A. (1977). Self-Efficacy: Toward a unifying theory of behavioral change. Psychological Review, 84(2), 191-215.

Bardin, L. (1977). Análise de conteúdo. Lisboa: Edições 70.

Bollinger, L. C. (2003). The need for diversity in higher education. Academic Medicine, 78(5), 431- 436.

Guarnieri, F. V. (2008). Cotas universitárias: perspectivas de estudantes em situação de vestibular. Dissertação de Mestrado, Programa de Pós-Graduação em Psicologia e Educação, Universidade de São Paulo, Ribeirão Preto, SP.

Guarnieri, F. V. \& Melo-Silva, L. L. (2007). Ações afirmativas na educação superior: rumos da discussão nos últimos cinco anos. Revista Psicologia e Sociedade, 19(2), 70-78.

Guimarães, A. S. A. (1997). A desigualdade que anula a desigualdade: notas sobre a ação afirmativa no Brasil. In J. Souza (Org.), Multiculturalismo e racismo: uma comparação BrasilEstados Unidos (pp. 233-242). Brasília, DF: Paralelo 15.

Htun, M. (2004). From "Racial democracy" to "affirmative actions": Changing state policy on race in Brazil. Latin American Research Review, 39(1), 60-89.
Lei $n$. 3524, de 28 de dezembro de 2000. (2000, 28 de dezembro). Dispõe sobre os critérios de seleção e admissão de estudantes da rede pública estadual de ensino em universidades públicas estaduais e dá outras providências. Acesso em 22 de junho, 2006, em http://alerjln1.alerj.rj.gov.br/contlei.nsf/bff0b8219 2929 c2303256bc30052cb1c/92c5d19ef1 cac546032569c400 69afa7?OpenDocument

Lei n. 3708, de 09 de novembro de 2001. (2001, 09 de novembro). Institui cota de até $40 \%$ (quarenta por cento) para as populações negra e parda no acesso à Universidade do Estado do Rio de Janeiro e à Universidade Estadual do Norte Fluminense, e dá outras providências. Acesso em 23 de junho, 2004, em http://alerjln1.alerj.rj.gov.br/contlei.nsf/f25edae7e64db53b 032564fe005262ef/827dde52958a6dd203256b030063db70 ?OpenDocument

Lent, R. W., Brown, S. D., \& Hackett, G. (1994). Toward a unifying social cognitive theory of career and academic interest, choice, and performance. Journal of Vocational Behavior, $45,79-122$.

Moehlecke, S. (2004). Fronteira da igualdade no ensino superior: excelência e justiça social. Tese de Doutorado, Universidade de São Paulo, São Paulo.

Munanga, K. A. (2004). A difícil tarefa de definir quem é negro no Brasil. Estudos Avançados, 18(50), 51-66.

Petruccelli, J. L. (2004). Mapa da cor no ensino superior brasileiro (Série Ensaios \& Pesquisas, Vol. 1). Brasília: Programa Políticas da Cor na Educação Brasileira, Governo Federal.

Projeto de Lei n. 1258, de 15 de fevereiro de 2000. (2000, 15 de fevereiro). Estabelece reserva de vagas nas universidades públicas estaduais para alunos egressos da rede pública de ensino. Acesso em 10 de outubro, 2004, em http://alerjln1.alerj. rj.gov.br/scpro99.nsf/57b07275a3e4c007832567040007cc4d/ 4bbac367077757e303256888005dcb1f?OpenDocument

Projeto de Lei n. 3627, de agosto de 2004. (2004, agosto). Dispõe sobre o ingresso nas universidades federais e dá outras providências. Congresso Nacional. Acesso em 23 de setembro, 2005, em http:/www.camara.gov.br/sileg/ integras/330424.pdf.

Projeto de Lei $n$. 3913, de 20 de agosto de 2008. (2008, 20 de agosto). Institui o sistema de reserva de vagas para estudantes egressos de escolas públicas nas instituições federais de educação superior, profissional e tecnológica. Acesso em 12 de novembro, 2008, em http://www.camara.gov.br/sileg/ prop_detalhe.asp?id $=407880$

Queiroz, D. M. \& Santos, J. T. (2006). Sistema de cotas - um debate: dos dados à manutenção de privilégios e poder. $E d u$ cação e Sociedade, 27(96), 717-737.

Rio de Janeiro. Laboratório de Políticas Públicas. (2006). Universidades com Cotas. Universidade Estadual do Rio de Janeiro. Acesso em 10 de agosto, 2006, em http://www.lpp-uerj.net/ olped/acoesafirmativas/universidades_com_cotas.asp

Rio de Janeiro. (2010). Programa políticas da Cor. Acesso em 10 de agosto, 2010, em http://www.politicasdacor.net

Salme, F. (2009). Um salto na qualidade de vida através das Cotas. Jornal eletrônico “O Dia”. Acesso em 10 de agosto, 2010, em http://odia.terra.com.br/portal/educação/html/2009/5/ um_salto_de qualidade_na_vida_atraves_das_cotas_15134. html

Santiago, N. E. A., Norberto, A. P., \& Rodrigues, S. M. C. (2008). $\mathrm{O}$ direito à inclusão: implantação de políticas de ações afirmativas nas IES públicas brasileiras. Experiência na UFC. Revista Pensar, 13(1), 136-147. 
Vieira, D. \& Coimbra, J. L. (2006). A auto-eficácia na transição para o trabalho. In R. G. Azzi \& S. A. J. Polydoro (Orgs.), Auto-eficácia em diferentes contextos (pp. 25-58). Campinas, SP: Ed. Alínea.

Whitaker, D. C. A. \& Onofre, S. A. (2006). Representações sociais em formação sobre os vestibulares dos estudantes de um cursinho comunitário da zona rural. Revista Brasileira de Orientação Profissional, 7(1), 45-55.

Recebido em: 24/12/2008

Revisão em: 28/03/2010

Aceite final em: 24/10/2010

Fernanda Vieira Guarnieri é Psicóloga pela Faculdade de Filosofia, Ciências e Letras de Ribeirão Preto, da Universidade de São Paulo (FFCLRP/USP). É mestre na área de Psicologia pela USP. Atua como Psicóloga na Prefeitura de Orlândia e é membro do grupo de estudos em
Orientação Profissional da FFCLRP. Endereço: Rua 11, 662, Bairro Centro, Orlândia/SP, Brasil. CEP 14620-000. Email: fervigua@yahoo.com.br

Lucy Leal Melo-Silva é Psicóloga, docente da Graduação e da Pós-Graduação em Psicologia da Faculdade de Filosofia, Ciências e Letras de Ribeirão Preto, da Universidade de São Paulo (FFCLRP/USP). Editora da Revista Brasileira de Orientação Profissional. Endereço: Universidade de São Paulo, FFCLRP, Departamento de Psicologia e Educação. Av. Bandeirantes, 3900, Monte Alegre, Ribeirão Preto/SP, Brasil. CEP 14040-901. Email: lucileal@ffclrp.usp.br

\section{Como citar:}

Guarnieri, F. V. \& Melo-Silva, L. L. (2010). Perspectivas de estudantes em situação de vestibular sobre as cotas universitárias. Psicologia \& Sociedade, 22(3), 486-498. 